\title{
The impact of anode design on fuel crossover of direct ethanol fuel cell
}

\author{
SETHU SUNDAR PETHAIAH ${ }^{1, *}$, JAYAKUMAR ARUNKUMAR ${ }^{2}$, MAXIMIANO RAMOS ${ }^{2}$, \\ AHMED AL-JUMAILY ${ }^{2}$ and NATARAJAN MANIVANNAN ${ }^{3}$ \\ ${ }^{1}$ Technische Universität München - Campus for Research Excellence and Technological Enterprise, 1 CREATE Way, \\ Singapore 138602, Singapore \\ ${ }^{2}$ I-BTec, Auckland University of Technology, Auckland 1142, New Zealand \\ ${ }^{3}$ Madurai Kamaraj University, Tamil Nadu 625002, India
}

MS received 1 May 2015; accepted 28 September 2015

\begin{abstract}
Direct-ethanol fuel cells (DEFCs) hold a promising future owing to its simple balance of plant operation and potential high-energy density. The significant challenges associated with it is the fuel crossover, which limits its performance and durability. In the present work, Pt-Pd nanocomposites were fused so as to find its impact on the anode design of DEFC. The current paper aimed to address these issues optimally and it also investigated the ethanol crossover by various electrochemical characterization techniques.
\end{abstract}

Keywords. Fuel cell; PEM; ethanol; anode design; fuel crossover; characterization.

\section{Introduction}

The upsurge in the use of internal combustion (IC) engine vehicles is causing considerable pollution problems in our urban conurbations [1] and as a consequence finding a clean and reliable power system for the forthcoming generation is viewed as a pie in the sky. Fuel cells belong to a class of reliable and renewable power systems [2], and their operating efficiency is as high as $85 \%$ for combined power and heat [3]. Their competence is credited owing to the fact that the chemical energy is directly converted to electrical energy, unlike traditional generators where the chemical energy is initially converted to the mechanical energy (by IC engine) and then to electrical energy (by generator) as illustrated in figure 1. In fuel cells, there is neither combustion nor emission and as a consequence there is high electrical efficiency than conventional generators of parallel size and rating.

Nevertheless, the storage and distribution issues of hydrogen are still challenging and in recent years many research interests have focused on direct alcohol fuel cells developments, because this simplifies the fuel storage and distribution issues [4]. Among the various liquid fuels, ethanol is advantageous owing to its low toxicity, high-energy density and renewable nature [5]. Furthermore, direct-ethanol fuel cell (DEFC) is a subset of proton exchange membrane fuel cells and retains all its benefits. The electrochemical reaction of DEFC, is that the ethanol is electro-oxidized at the anode and oxygen is reduced at the cathode according to reactions (1) and (2), respectively, to result in the generation of electricity and heat [6].

$$
\text { Anode: } \mathrm{C}_{2} \mathrm{H}_{5} \mathrm{OH}+3 \mathrm{H}_{2} \mathrm{O} \rightarrow 2 \mathrm{CO}_{2}+12 \mathrm{H}^{+}+12 \mathrm{e}^{-},
$$

\footnotetext{
*Author for correspondence (sundar.pethaiah@tum-create.edu.sg)
}

$$
\begin{aligned}
& \text { Cathode: } 3 \mathrm{O}_{2}+12 \mathrm{H}^{+}+12 \mathrm{e}^{-} \rightarrow 6 \mathrm{H}_{2} \mathrm{O}, \\
& \text { Overall: } \mathrm{C}_{2} \mathrm{H}_{5} \mathrm{OH}+3 \mathrm{O}_{2} \rightarrow 2 \mathrm{CO}_{2}+3 \mathrm{H}_{2} \mathrm{O} .
\end{aligned}
$$

From the commercial perspective also ethanol is an attractive alternative because it comes with a supply chain that is already well established and also remains the easier fuel to work with for widespread use by consumers. Thus direct ethanol-based fuel cell power systems can be an appropriate candidate for portable and transport applications. There are several factors that determine the performances and durability of the DEFC, and among them ethanol crossover is an important challenge. In general ethanol crossover is lower than methanol due to the higher molecular weight of ethanol compared with methanol [7]; however, it is not negligible [8]. The negative effects of ethanol crossover include decrease in the cathode potential and reduced overall efficiency. It also has potential to poison the cathode catalyst and wasting of fuel [9]. In order to mitigate the effect of ethanol crossover, a number of techniques have been reported and the modification of electrolyte membrane based on Nafion membrane is one of the promising techniques [3,7-9]. It is widely reported in literature that the catalysed membrane preparation is an appropriate method to mitigate methanol and ethanol crossover. The surface modification of Nafion membrane and the incorporation of Pd and Pd alloy into Nafion membrane have been developed to reduce the methanol crossover [10], moreover, $\mathrm{Pd}$ is impermeable to methanol and sufficient permeable for hydrogen (proton) [11]. The Pt-Pd alloy catalyst with an appropriate ratio exhibit very good resistance against $\mathrm{CO}$ poisoning effect [12]. Hence, in this study, Pt-Pd impregnated nanocomposite polymer electrolyte membrane (PEM) was prepared and the effect of anode structure design on DEFC performance and ethanol crossover was investigated. Diverse electrochemical 


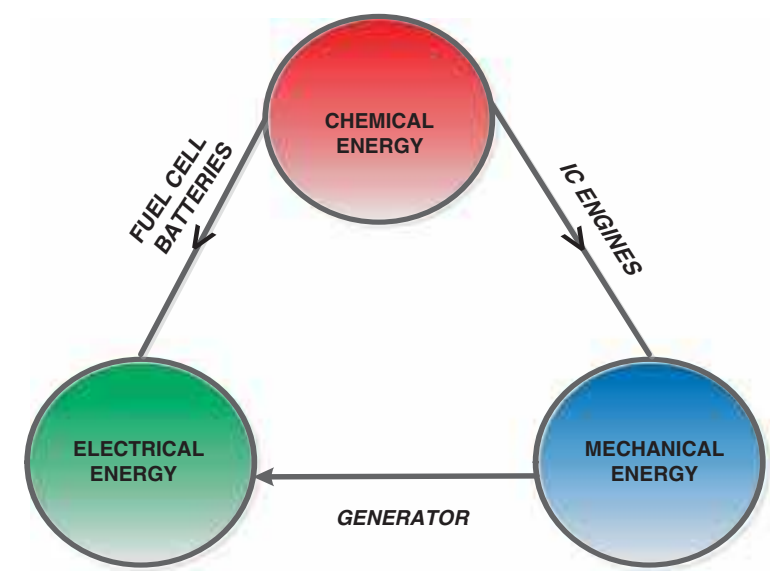

Figure 1. Energy conversion path of conventional power systems.

characterization techniques are presented to investigate the impact of Pt-Pd impregnated nanocomposites and compare it with normal membrane electrode assembly (MEA).

\section{Experimental}

\subsection{Preparation of $P t-P d$ composite membrane}

The methodology used for membrane pre-treatment and Pt-Pd impregnated nanocomposite membrane preparation method has been reported already in our previous work [13]. The Pt-Pd impregnated nanocomposites MEA were prepared by hot pressing the Pt-Pd-coated Nafion membrane between the two gas diffusion electrodes with $1 \mathrm{mg} \mathrm{cm}^{-2}$ of $40 \%$ $\mathrm{Pt} / \mathrm{C}$ catalyst on anode side and $3 \mathrm{mg} \mathrm{cm}{ }^{-2}$ of Pt black on cathode side at $120^{\circ} \mathrm{C}$ with a pressure of 1000 psi for 5 min. Pt-Pd was deposited on one side of Nafion membrane and used as the anode of DMFC. To prepare the gas diffusion electrode, the catalyst was suspended in water and ultrasonicated by adding isopropyl alcohol and $5 \mathrm{wt} \%$ of Nafion ionomer. The obtained slurry was coated on the teflonized carbon cloth. Adding another layer of catalyst $(40 \%$ $\mathrm{Pt} / \mathrm{C}$ ) with Nafion ionomer helps to ensure good current collection from the thin Pt-Pd/Nafion layer and provide good contact with the gas diffusion layer [14]. Present research work is mainly focused on to study only the influence of $\mathrm{Pt}-\mathrm{Pd} / \mathrm{Nafion}$ layer on ethanol crossover, hence superior catalyst was avoided for ethanol oxidations (PtRu, PtSn, etc.) and used basic Pt/C catalyst in the present study. For comparative evaluations, to prepare the normal MEA the catalyst was suspended in water and ultrasonicated by adding $5 \mathrm{wt} \%$ of Nafion ionomer (Dupont) and isopropyl alcohol. The obtained slurry was coated on the teflonized carbon paper (SGL, Sigracet) with the catalyst loading of $3 \mathrm{mg} \mathrm{cm}^{-2}$ of $40 \% \mathrm{Pt} / \mathrm{C}$ for anode side and $3 \mathrm{mg} \mathrm{cm}^{-2}$ of Pt black for the cathode side. All MEAs anode side gas diffusion electrodes were hot pressed with uniform pores (figure 2). To facilitate the comparative study, the total loading of electrocatalyst,

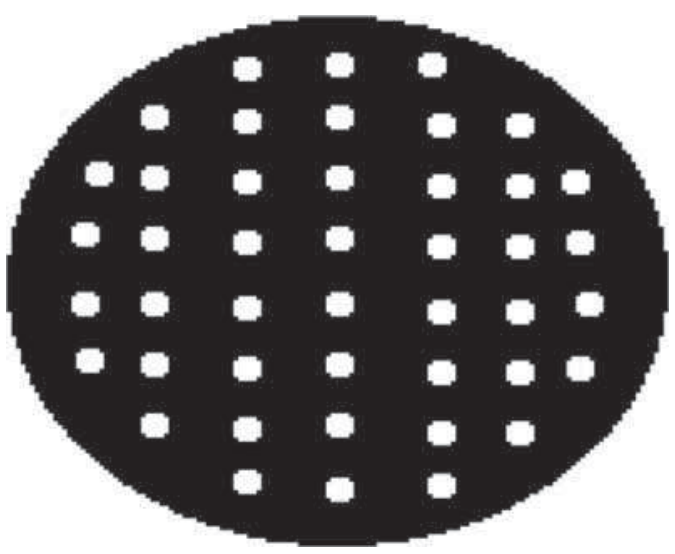

Figure 2. Gas diffusion layer with uniform holes design.

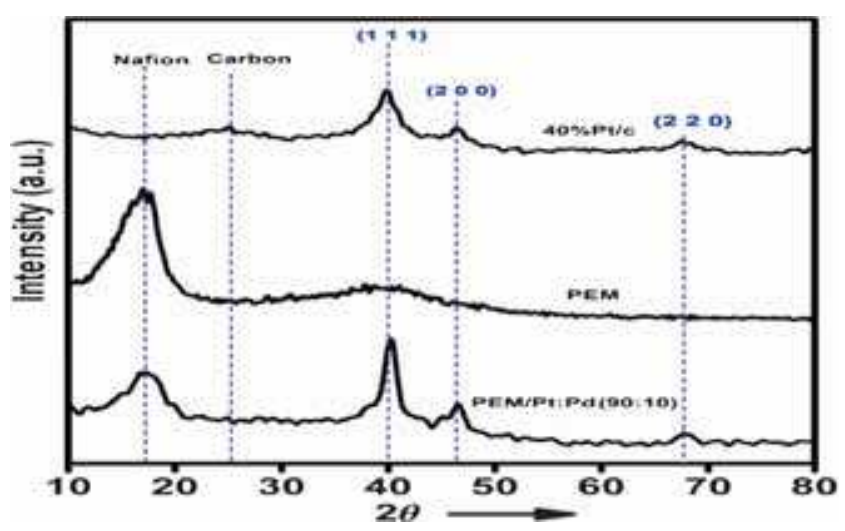

Figure 3. X-ray diffraction analysis of Pt-Pd (90:10) layered Nafion 117 membrane, plain Nafion 117 membrane and 40\% Pt/C catalyst.

hot-pressing parameters and geometrical area of electrodes were kept constant.

\subsection{Structural characterizations}

X-ray diffraction (XRD) pattern of Pt-Pd nanocomposite membranes were acquired at room temperature with X'pert PRO PANalytical diffractometer using $\mathrm{Cu}-\mathrm{K}_{\alpha}$ radiation as the source and operated at $40 \mathrm{kV}$. The sample was scanned in the $2 \theta$ ranging from $10^{\circ}$ to $80^{\circ}$ for $2 \mathrm{~s}$ in the stepscan mode. Surface morphology, cross-sectional view and energy-dispersive X-ray spectrometer (EDX) of the Pt-Pd impregnated nanocomposite membranes were characterized using scanning electron microscopy (SEM; Horiba, EMAX) with an EDX analyzer (JEOL JSM-6400).

\subsection{Single cell assembly and electrochemical characterizations}

Single cell experiments were performed by placing the Pt-Pd nanocomposite MEA between two silicone rubber gaskets of 
thickness $0.25 \mathrm{~mm}$ and inserted in between two serpentine grooved graphite plates with $5 \mathrm{~cm}^{2}$ active areas. The fixture parts were clamped together using nuts and bolts by applying uniform torque to assemble the single cell. Provision has been made to heat the cell with temperature control. Inlet and exit ports are available for feeding the reactants and removal of products. For comparative study, a single cell with normal MEA also assembled.

The ethanol crossover measurement was detected by a potentiostat/galvanostat apparatus (Autolab). The ethanol fed anode side of MEA was used as a counter electrode and also as a reference electrode. High-purity nitrogen (99.99\%) gas was fed to the cathode at a flow rate of $100 \mathrm{ml} \mathrm{min}^{-1}$ under a pressure of 2 atm and acts as working electrode. When a potential was applied, the ethanol that had permeated from the anode to the cathode was electrochemically converted in the cathode side, hydrogen ions were then sent from the cathode to the anode. The amount of ethanol crossover was shown as the ethanol oxidation current at the cathode. The potential vs. dynamic hydrogen reference electrode was performed in the range of $0-1 \mathrm{~V}$. The proton conductivity of the membrane was determined by an electrochemical impedance technique using a Potentiostat/Galvanostat over a frequency range between 6000 and 0.1. The amplitude of the AC-voltage was $5 \mathrm{mV}$.

\section{Results and discussions}

\subsection{Physical characterizations}

XRD patterns of Pt-Pd layered Nafion 117 membrane, plain Nafion 117 membrane and 40\% Pt/C catalyst are shown in

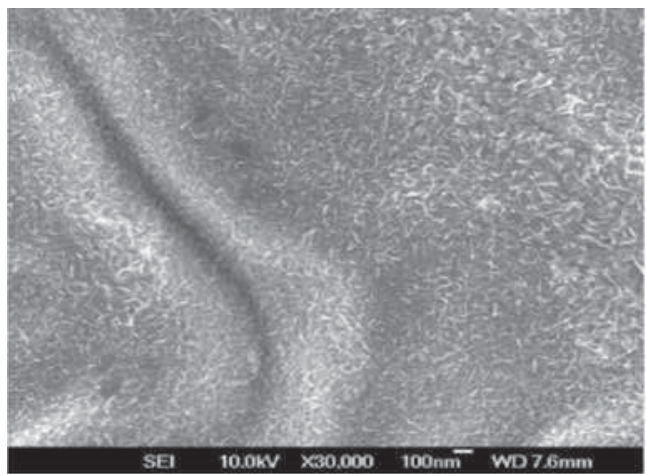

(a)

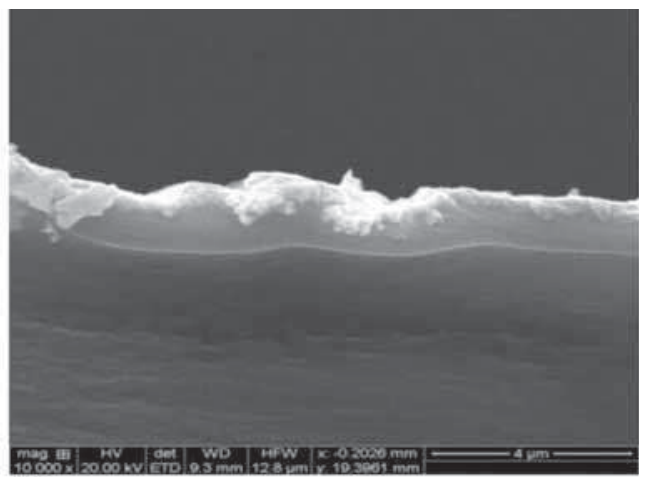

(b)

Figure 4. FESEM image of Pt-Pd (90:10) bimetallic layered Nafion ${ }^{\circledR} 117$ membrane: (a) surface morphology and (b) cross-sectional view.

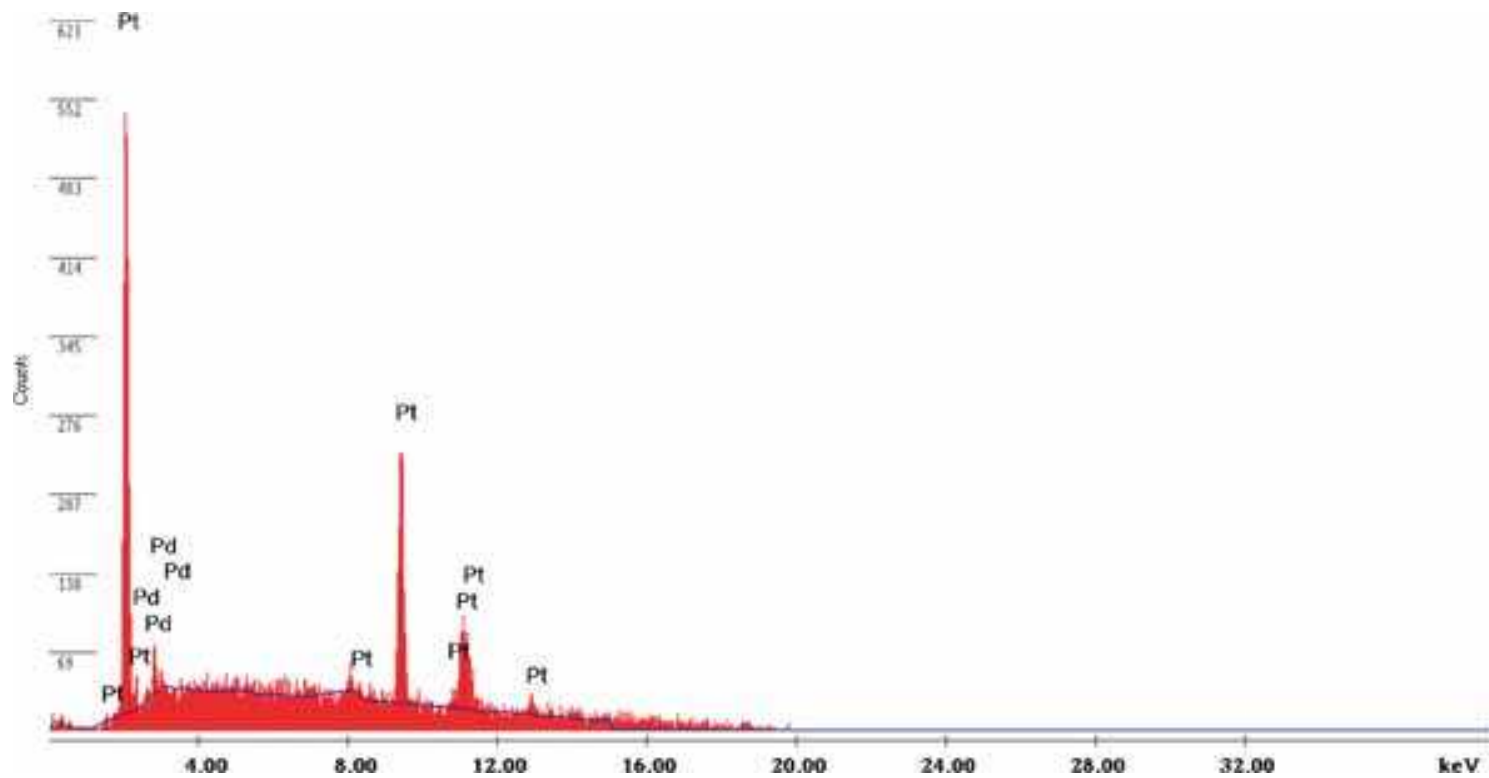

Figure 5. EDX spectrum of Pt-Pd (90:10) bimetallic layered Nafion ${ }^{\circledR} 117$ membrane. 
figure 3. The first peak is located at about $16.5^{\circ}$ and $24.8^{\circ}$ in the XRD pattern and is associated with the Nafion membrane and Vulcan XC-72 carbon support, respectively $[15,16]$. The other peaks of Pt-Pd layered Nafion membrane demonstrated the main characteristic peaks at $2 \theta=40^{\circ}, 47^{\circ}$ and $68^{\circ}$ corresponding to the (1 111$),\left(\begin{array}{lll}2 & 0 & 0\end{array}\right)$ and (2 200$)$ lattice planes of face-centred cubic (fcc) structure of Pt and Pd [14]. However, there is no characteristic peak of metallic $\mathrm{Pd}$ or $\mathrm{Pd}$ oxides, but their presence cannot be discarded because they may be present in a very small particle size or even in an amorphous form [17]. Similar observations were obtained for $\mathrm{Pt} / \mathrm{Ru}$-based catalyst layered systems by Fujiwara et al [18]. The loading of Pd and Pt bimetallic catalysts on the Nafion membrane was confirmed from the EDX analysis. The XRD patterns of commercial $40 \% \mathrm{Pt} / \mathrm{C}$ catalyst, has its peak at $2 \theta=39.8^{\circ}, 46.5^{\circ}$ and $67.71^{\circ}$ corresponding to the $\left(\begin{array}{lll}1 & 1 & 1\end{array}\right)$, (2 00 ) and (2 20 ) lattice planes, which confirms the fcc cubic structure of Pt. From the XRD measurements, the average particle size of the Pt-Pd was calculated from the broadening of the (1 111 1 diffraction peaks using Debye-Scherrer's relation. The calculated average particle size of $\mathrm{Pt}$ coated on the membrane surface and $40 \% \mathrm{Pt} / \mathrm{C}$ catalysts was 5.4 and $3 \mathrm{~nm}$, respectively.

Surface morphology and cross-sectional view of the PtPd bimetallic layered Nafion ${ }^{\circledR} 117$ membranes are shown in figure $4 \mathrm{a}$ and $\mathrm{b}$, respectively. It was observed that the bimetallic particles were uniformly deposited onto the membrane and the particles were closely packed with even particles size distribution. In order to confirm the presence of bimetallic particles and the coating thickness, the study was extended to EDX and cross-sectional image analyses, respectively. Figure 5 shows a cross-section of the Pt-Pd layered Nafion membrane. The thickness of the bimetallic layer is about a few microns and there is no free gap observed between the bimetallic layer and the membrane which restrict the ethanol crossover. EDX spectra of the Pt-Pd bimetallic layered Nafion ${ }^{\circledR} 117$ membrane (figure 6) also confirmed the $\mathrm{Pt}$ and Pd particles distribution which is consistent with the cross-sectional image of the sample and with the XRD result. The obtained atomic and weight percentage of $\mathrm{Pt}$ and $\mathrm{Pd}$ particles are given in table 1.

\subsection{Electrochemical characterizations}

Figure 6 shows the schematic of anode side impregnated nanocomposite MEA, which contains Pt-Pd layer, Pt/C catalyst layer with microporous layer and Teflon-coated gas diffusion medium (carbon cloth). The main difference between normal MEA and impregnated nanocomposite MEA is a thin layer of Pt-Pd is coated in Nafion membrane. This PtPd layer restricts the ethanol crossover, which prevents the mixed potential and possible poisoning of cathode catalyst layer. The ethanol crossover current density $v s$. the applied voltages of conventional and Pt-Pd impregnated MEA is shown is figure 7. It is assumed that the current generated in this measurement was from that electrochemically converted in cathode $[7,8]$. When $1 \mathrm{M}$ of ethanol was fed at

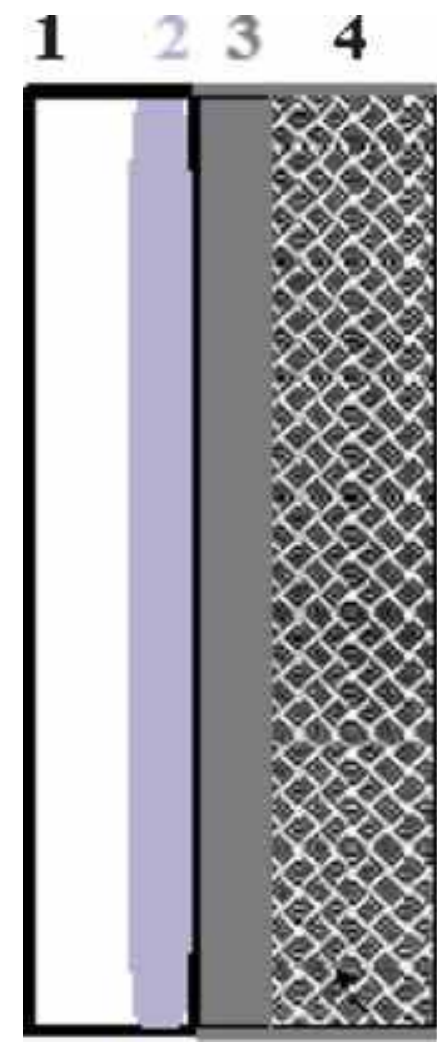

Figure 6. Schematic of the anode structure (1. Nafion membrane, 2. Pt-Pd layer, 3. Pt/C catalyst layer with MPL and 4. gas diffusion medium).

$80^{\circ} \mathrm{C}$, the ethanol crossover current density decreased from $62 \mathrm{~mA} \mathrm{~cm}{ }^{-2}$ for conventional MEA to $51 \mathrm{~mA} \mathrm{~cm}{ }^{-2}$ for $\mathrm{Pt}-\mathrm{Pd}$ impregnated MEA at $0.6 \mathrm{~V}$. This is mainly due to suppression of ethanol crossover by Pt-Pd layer.

The Nafion membrane was made of hydrophobic backbone structure and a hydrophilic side chain. In a wellhydrated membrane, there will be approximately 20 water molecules for each $\mathrm{SO}_{3}$ side chain $[9,19]$. The impregnation solutions of Pt and Pd occupy the hydrated regions and precipitated in the hydrophilic region and then reduce the water molecules concentration, which then possibly decreases the proton conductivity and ethanol crossover. However, palladium is hydrogen (proton) permeable metal [20], the Pt$\mathrm{Pd} / \mathrm{Nafion}$ membranes selectively transport the hydrogen ions and restrict the ethanol permeations. Hence, the developed anode's design does not affect the proton conductivity of membrane (table 2).

The polarization studies are performed in the single cell with the Pt-Pd impregnated nanocomposite MEA and normal MEA as shown in figure 8 . Briefly, $1 \mathrm{M}$ ethanol is fed to the anode and non-humidified oxygen with $2 \mathrm{~atm}$ cathodic pressure. An improvement in cell performance was observed with the Pt-Pd impregnated nanocomposite than the normal one. For a quick overview Pt-Pd nanocomposite MEA exhibits a peak power density of $14.5 \mathrm{~mW} \mathrm{~cm}$, this enhanced performance of DEFC is due to the reduced crossover. Moreover, the increased open-circuit voltage 
Table 1. XRD and EDX characteristics of the prepared samples.

\begin{tabular}{lccc}
\hline & \multicolumn{2}{c}{ EDX } \\
\cline { 3 - 4 } $\begin{array}{l}\text { Metal compositions } \\
\text { in solution (at\%) }\end{array}$ & $\begin{array}{c}\text { XRD_average } \\
\text { particle size (nm) }\end{array}$ & $\begin{array}{c}\text { Metal compositions } \\
\text { (at\%) }\end{array}$ & $\begin{array}{c}\text { Metal compositions } \\
\text { (wt\%) }\end{array}$ \\
\hline Pt-Pd (90:10) & 5.4 & $94.61: 5.39$ & $96.98: 3.02$ \\
\hline
\end{tabular}

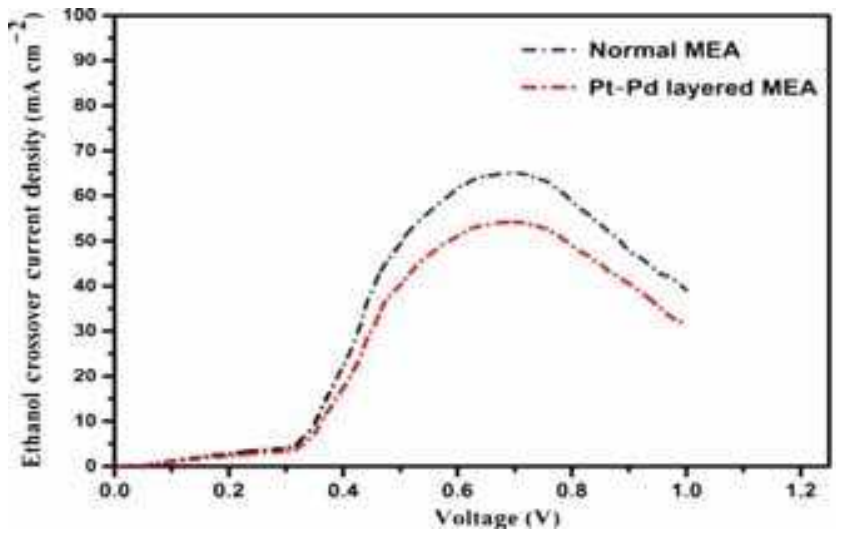

Figure 7. Ethanol crossover rate measurement of conventional and $\mathrm{Pt}-\mathrm{Pd}$ impregnated MEA.

Table 2. Fitted impedance parameters.

\begin{tabular}{lc}
\hline Membrane & $R\left(\Omega \mathrm{cm}^{2}\right)$ \\
\hline Normal MEA & 0.38 \\
Pt-Pd/Nafion 117 & 0.35 \\
\hline
\end{tabular}

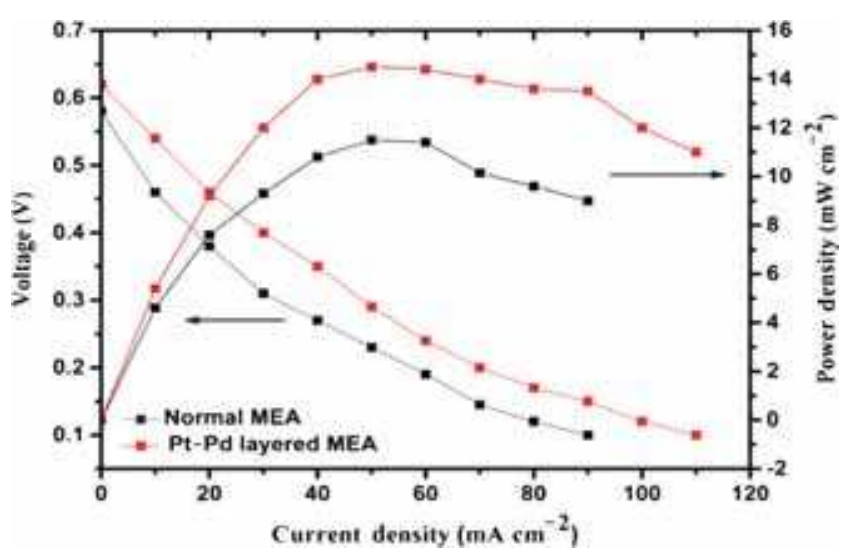

Figure 8. Single cell performance comparison of Pt-Pd layered MEA and normal MEA at $80^{\circ} \mathrm{C}$.

(OCV) of the Pt-Pd nanocomposite MEA also confirmed the reduced crossover. The ethanol crossover through the membrane causes a significant reduction of the cathode potential due to the direct oxidation of ethanol at the cathode catalyst. This side reaction leads to the larger mixed potential; as a result in a decreased value of the OCV is observed in normal MEA.

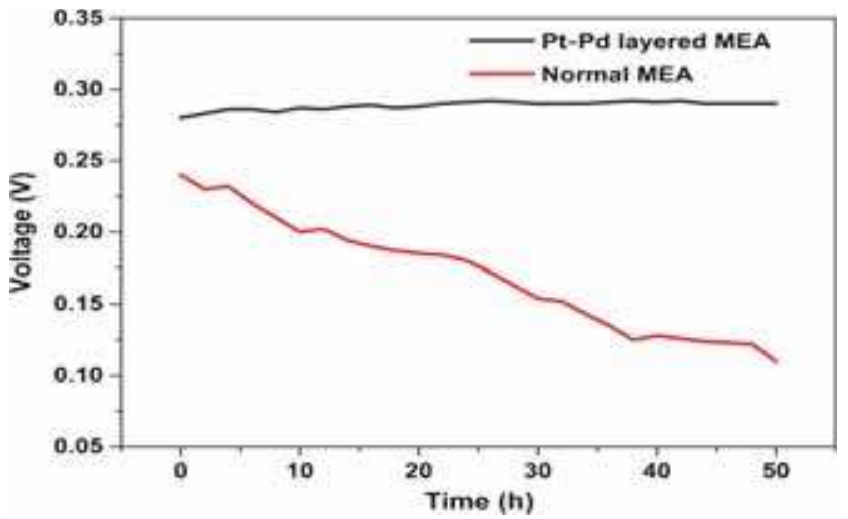

Figure 9. Degradation rate of Pt-Pd layered MEA.

The stability of the Pt-Pd impregnated nanocomposite MEA was studied at an intermittent discharge rate for $50 \mathrm{~h}$. Figure 9 shows the voltage response characteristics of normal and Pt-Pd layered MEA under a constant current density of $50 \mathrm{~mA} \mathrm{~cm}{ }^{-2}$ at $80^{\circ} \mathrm{C}$. The cell voltage increased slowly initially with the increase in time and then reached a steadystate value of about $0.292 \mathrm{~V}$ at $50 \mathrm{~mA} \mathrm{~cm}^{-2}$. During $50 \mathrm{~h}$ of operation, no sharp performance degradation was observed for Pt-Pd layered MEA. However, a sharp voltage drop was observed for the normal MEA over the $50 \mathrm{~h}$ of operation.

\section{Conclusions}

The anode design plays a vital role in the performance of DEFC as the active electrochemical reaction takes place at that juncture and the proposed paper investigates on that possibility to enhance the design that would significantly retard the ethanol crossover and possibly improve the durability. The performance, dynamic characteristics and durability of the DEFC can also be considerably improved by this proposed design, which are very much critical for its commercialization.

\section{References}

[1] Shukla A, Jackson C and Scott K 2003 Bull. Mater. Sci. 26 207

[2] Kumar J A, Kalyani P and Saravanan R 2008 Int. J. Electrochem. Sci. 3961 
[3] Kordesch K V and Simader G R Fuel cell systems: Sections 4.6-4.8. Fuel cells: and their applications 133-179

[4] Wan C-H and Chen C-L 2009 Int. J. Hydrogen Energy 34 9515

[5] Pethaiah S S, Subiantoro A and Stimming U 2013 ECS Trans. 533

[6] Datta J et al 2009 Bull. Mater. Sci. 32643

[7] Ekdharmasuit P, Therdthianwong A and Therdthianwong S 2014 Int. J. Hydrogen Energy 391775

[8] Song S et al 2005 J. Power Sources 140103

[9] Kamarudin M et al 2013 Int. J. Hydrogen Energy 389438

[10] Jung E et al 2007 Int. J. Hydrogen Energy 32903

[11] Hejze T et al 2005 J. Power Sources 14021
[12] Ding K et al 2013 Electrochim. Acta 100147

[13] Pethaiah S S et al 2015 RSC Adv. 5981

[14] Song Y, Wei Y, Xu H, Williams M, Liu Y, Bonville L J, Russell Kunz H and Fenton J M 2005 J. Power Sources 141 250

[15] Ludvigsson M, Lindgren J and Tegenfeldt J 2000 J. Electrochem. Soc. 1471303

[16] Huang Q et al 2006 Electrochem. Commun. 81220

[17] Thanasilp S and Hunsom M 2011 Renew. Energy 361795

[18] Fujiwara N et al 2002 Electrochim. Acta 474079

[19] Samms S, Wasmus S and Savinell R 1996 J. Electrochem. Soc. 1431498

[20] Kim Y J et al 2004 Electrochim. Acta 493227 